\title{
Evaluation of intra- and inter-rater reliability and concurrent validity of the Italian version of the Jebsen-Taylor Hand Function Test in adults with rheumatoid arthritis
}

Hand Therapy

0(0) 1-7

(C) The Author(s) 2019

Article reuse guidelines:

sagepub.com/journals-permissions DOI: $10.1177 / 1758998319843554$ journals.sagepub.com/home/hth

@SAGE

\author{
Andrea Savona', Luca Ferralis', Marco Saffioti ${ }^{2}$, \\ Marco Tofani ${ }^{3}$ (1), Marta Nobilia ${ }^{4}$, Greta Culicchia ${ }^{4}$, \\ Anna Berardi', Annamaria Servadio ${ }^{2}$ and Giovanni Galeoto ${ }^{5}$
}

\begin{abstract}
Introduction: In rheumatoid arthritis, a reduction in hand function can lead to a decrease in health, with a consequent limitation of daily life activities and restriction in social participation. Evaluation plays a decisive role in the functional recovery process and in rehabilitation programs. The Jebsen-Taylor Hand Function Test is one of the most widely used non-diagnosis-specific assessment tools in rehabilitation. The aim of the study was to evaluate the intra-rater and interrater reliability and concurrent validity of the Italian version of the Jebsen-Taylor Hand Function Test (JTHFT-IT) in a population with rheumatoid arthritis.

Methods: The test's reliability and validity were assessed by following international guidelines. Its internal consistency and intra- and inter-rater reliability were examined using Cronbach's alpha coefficient and the intraclass correlation coefficient, respectively. Its concurrent validity was evaluated using Pearson's correlation coefficient with a dynamometer instrument.

Results: The test was given to 108 people with rheumatoid arthritis. Cronbach's alpha reported a value of $0.9 \mathrm{I}$ for the dominant hand and 0.87 for the non-dominant hand. Intra- and inter-rater reliability were evaluated with a subgroup of 30 individuals. Intraclass correlation coefficients ranged from 0.46 to 1.00 in the dominant and non-dominant hands. Pearson's correlation between subtests and the dynamometer ranged from -0.14 to -0.59 .

Conclusions: The present study supports the use of the JTHFT-IT as a measure of hand functionality in people with rheumatoid arthritis. It is an important tool for Italian professionals and it can be useful both in clinical practice to evaluate improvement after rehabilitation treatments and for research in hand rehabilitation.
\end{abstract}

\section{Keywords}

Italian, outcome measure, rheumatoid arthritis, reliability, validity

Date received: 31 January 2019; accepted: 22 March 2019

\section{Introduction}

According to the World Health Organization, the prevalence of rheumatoid arthritis (RA) in the world is between 0.3 and $1 \%$, with a greater presence among women and in rich countries. ${ }^{1}$ RA most commonly affects the joints of the hands, feet, wrists, elbows, knees, and ankles. A reduction in hand function can lead to a decrease in health, with a consequent limitation of daily life activities and restriction in social
'Sapienza University of Rome, Rome, Italy

${ }^{2}$ Department of Health Professions, Tor Vergata Hospital of Rome, Rome, Italy

${ }^{3}$ Department of Neuroscience and Neurorehabilitation, Bambin Gesù Pediatric Hospital, Rome, Italy

${ }^{4}$ IRCCS MultiMedica - UOC Hand Surgery, Milan, Italy

${ }^{5}$ Department of Public Health, Sapienza University of Rome, Rome, Italy

\section{Corresponding author:}

Giovanni Galeoto, Piazzale Aldo Moro 5, Rome, Italy.

Email: giovanni.galeoto@uniromal.it 
participation. Hand rehabilitation is therefore of primary importance to ensure the maintenance of autonomy and independence, with the aim of achieving the highest degree of social and work integration. ${ }^{2}$ Early diagnosis and treatment can make a difference in controlling RA and preventing deformity. Evaluation plays a decisive role in the functional recovery process and must be carried out at regular intervals throughout the treatment period in order to record progress and modify the rehabilitation program, if necessary. ${ }^{2}$

Functional abilities depend on anatomical integrity, muscle strength, sensation, and dexterity; these elements are influenced by age, gender, and mental state. ${ }^{2,3}$ In a recent article titled "Systematic Review of Measures of Impairment and Activity Limitation for Persons With Upper Limb Trauma and Amputation," "five tools were assessed as the highest rated performance measures; of these, the JebsenTaylor Hand Function Test (JTHFT) was one of the most widely used non-diagnosis-specific assessment tools in rehabilitation due to its simplicity, convenience, and speed of administration. The JTHFT provides objective measurement of standardized tasks relative to norms; it evaluates broad aspects of those hand functions commonly used in everyday activities, and it can be administered in a short time by using readily available materials. It was designed in 1969 by Jebsen et al. as a performance-based measure that assesses fine and manual finger dexterity through the use of seven timed subtests related to functional tasks. ${ }^{5}$ From the perspective of the International Classification of Functioning categories, it is classified as an activity scale, as it measures changes in functional activities. ${ }^{6}$ The JTHFT is very versatile for the assessment of the upper limb and is widely used in many countries in the world; it has been translated and validated in Australian-English, ${ }^{7}$ Chinese, ${ }^{8}$ Portuguese, ${ }^{9}$ and Italian. ${ }^{10}$ The JTHFT has also been validated for different disorders affecting the upper limbs, including hemiparesis, ${ }^{9}$ muscular dystrophies, ${ }^{11}$ stroke, ${ }^{12}$ Parkinson's disease, ${ }^{13}$ and carpal tunnel syndrome. ${ }^{14}$

The main advantage of the JTHFT is to provide an objective measure of hand function by employing functionally relevant tasks that have good intra- and interrater reliability. It was originally tested on an RA population; therefore, the aim of this study was to test the validity and reliability of the Italian version in Italian individuals with RA.

\section{Methods}

This study was conducted by a research group composed of medical doctors and rehabilitation professionals from the Sapienza University of Rome and from the Rehabilitation \& Outcome Measure Assessment Association. ${ }^{15}$

\section{Participants}

The sample was recruited from January to October 2016 in the national territory from the National Association of Rheumatic Disease and the hand surgery and rheumatology clinics of two university hospitals in Rome, Italy. The people with RA that accessed the hospital were screened and adults with a confirmed diagnosis were informed about the procedures and purposes of the study and were asked to participate. The following inclusion/exclusion criteria were applied to the eligible and interested persons: a diagnosis of RA, age over 18 years old, a primary education level at minimum, the ability to understand instructions and perform the scale activities, and a signed informed consent document. ${ }^{16,17}$ People with severe deformities or high level of pain, as determined by clinical screening, were excluded because of their inability to perform the activities of the JTHFT.

\section{Validation procedures}

Three clinicians (two occupational therapists and one physical therapist) screened all patients for their recruitment and applied the inclusion/exclusion criteria. Once enrolled, these clinicians collected demographic and clinical variables, and at the rheumatology clinics of two university hospitals in Rome, they administered the outcome measures to all patients included. The first testing session included the JTHFT-IT administration and the dynamometer measurement. After two days, a subsample was tested again by a different clinician in order to evaluate inter-rater reliability. Finally, to study the intra-rater reliability, the JTHFT-IT was re-administered after seven days in a subsample by the same assessor of the first administration. The tests were always administered in the same order: first JTHFT and then Jamar.

\section{Instruments}

The JTHFT consists of seven unilateral items that are administered using standardized procedures and verbal instructions and performed first with the non-dominant hand and then with the dominant hand. The functional tasks include writing a 24-letter, third-grade reading difficulty sentence; turning $3^{\prime \prime} \times 5^{\prime \prime}(7.62 \mathrm{~cm} \times 12.7$ $\mathrm{cm}$ ) cards in simulated page turning; picking up small common objects including pennies, paper clips, and bottle caps and placing them in a container; stacking checkers; simulated feeding; and moving light cans and heavier ( 1 pound) cans. The subtests are scored by recording the number of seconds required to complete 
each task. Increased time to complete the test is related to decreased hand function. A stopwatch was used to time the completion of each. The JTHFT-IT showed in the Italian validation on healthy population an intraclass correlation coefficient (ICC) for intra-rater reliability ranging from 0.297 to 0.715 for the dominant hand and 0.584 to 0.892 for the non-dominant hand. Normative data from the original scoring system are available for dominant and non-dominant hands. ${ }^{10}$ In the same study, the Pearson's test revealed a strong correlation between all items and between the items and the gold standard (Jamar dynamometer), represented by gripping force. Consistent with previous studies, the instrument used in this study was the Jamar $\mathrm{J} 00105,{ }^{18}$ a dynamometer model that calculates the strength of the flexor muscles of the hand. When grip is measured, the arm should be at the patient's side with elbow flexed at approximately $90^{\circ}$ and the forearm in neutral. The wrist should be at neutral but no more than $30^{\circ}$ of extension or $15^{\circ}$ of ulnar deviation. When ready the patient is encouraged to squeeze the dynamometer with maximum isometric effort, which is maintained for about $5 \mathrm{~s}$. This instrument is scored using force production in kilograms $(0-90)$ or pounds (0-200).

\section{Data analyses}

The reliability of the JTHFT-IT was assessed by following international guidelines ${ }^{19}$ in terms of internal consistency and test-retest reliability. Internal consistency was determined by calculating Cronbach's alpha, which was considered acceptable if $>0.7$. Test-retest reliability was calculated by using the ICC with a $95 \%$ confidence interval. ICC values greater than 0.75 are a minimum requirement to use the instrument in group measurements. The concurrent validity of the JTHFT-IT was studied by calculating the Pearson's correlation coefficient when comparing the JTHFT-IT with the dynamometer instruments. ${ }^{18}$ Concurrent validity is one approach of construct validity that estimates individual performance on different tests at approximately the same time; it can tell how accurately a measurement can predict criteria or indicators of a construct in the real world. The following ranges were considered in interpreting the results: $\rho>0.70=$ strong correlation, $0.50<\rho<0.70=$ moderate correlation, and $\rho<0.50=$ weak correlation.

All statistical analyses were performed using the Statistical Package for the Social Sciences (SPSS) version 20.0 for Windows. The descriptions of the variables were carried out using frequency tables, means, and standard deviations. The significance level was set as a p-value less than or equal to 0.05 .

\section{Results}

\section{Sample characteristics}

For this study, 126 individuals were considered eligible by the researchers after the first screening using inclusion and exclusion criteria, of these five were excluded because they had severe deformities or a high level of pain. Out of the 121 remaining, 108 people agreed to participate and were included in this study. The demographic and clinical characteristics of the participants are reported in Table 1.

\section{Reliability and validity}

The internal consistency of the JTHFT-IT, that assesses the interrelatedness of the items, was calculated with Cronbach's alpha and showed values of 0.53 for the dominant hand and 0.46 for the non-dominant hand. From the evaluation of the weight of the items (item-total), item 1 (writing) was found to be unrelated to the others. When the first item was eliminated, Cronbach's alpha was 0.91 for the dominant hand and 0.87 for the non-dominant hand as reported in Table 2. Intra- and inter-rater reliability were assessed in a subsample of 30 individuals. A high degree of reliability, that means a high degree of agreement among repeated administrations performed by a single rater (intra-rater) or different raters (inter-rater), was observed for the JTHFT-IT as reported in Tables 3 and 4. Taking into account the comparisons between

Table I. Demographic characteristics of the 108 participants in the reliability study JTHFT-IT in rheumatoid arthritis population.

\begin{tabular}{|c|c|c|}
\hline & Mean & $\begin{array}{l}\text { Standard } \\
\text { deviation }\end{array}$ \\
\hline \multirow[t]{2}{*}{ Age } & 59.90 & 12.62 \\
\hline & Frequency & Percent \\
\hline \multicolumn{3}{|l|}{ Gender } \\
\hline Male & 20 & 18.5 \\
\hline Female & 88 & 81.5 \\
\hline \multicolumn{3}{|l|}{ Right hand } \\
\hline Dominant hand & 104 & 96.3 \\
\hline Most affected hand & 92 & 85.2 \\
\hline \multicolumn{3}{|l|}{ Education } \\
\hline Primary education & 12 & II.I \\
\hline Secondary & 67 & 62 \\
\hline Post-secondary education & 29 & 26.9 \\
\hline \multicolumn{3}{|l|}{ Profession } \\
\hline Employed & 26 & 24.1 \\
\hline Retired & 42 & 38.9 \\
\hline Housewife & 24 & 22.2 \\
\hline Unemployed & 8 & 7.4 \\
\hline Others & 8 & 7.4 \\
\hline
\end{tabular}


Table 2. Item-total analysis: Cronbach's alpha for each item in the reliability study JTHFT-I in rheumatoid arthritis population.

\begin{tabular}{|c|c|c|c|c|}
\hline & \multicolumn{2}{|l|}{ Non-dominant hand } & \multicolumn{2}{|l|}{ Dominant hand } \\
\hline & $\begin{array}{l}\text { Corrected item-total } \\
\text { correlation }\end{array}$ & $\begin{array}{l}\text { Cronbach's alpha } \\
\text { if item deleted }\end{array}$ & $\begin{array}{l}\text { Corrected item-total } \\
\text { correlation }\end{array}$ & $\begin{array}{l}\text { Cronbach's alpha } \\
\text { if item deleted }\end{array}$ \\
\hline Writing a 24-letter & 0.30 & 0.87 & 0.25 & 0.91 \\
\hline Stacking checkers & 0.58 & 0.42 & 0.56 & 0.46 \\
\hline Turning over a $3 \times 5^{\prime \prime}$ card & 0.54 & 0.40 & 0.59 & 0.46 \\
\hline Pick up small common object & 0.35 & 0.40 & 0.21 & 0.51 \\
\hline Simulate feeding using teaspoon & 0.69 & 0.39 & 0.76 & 0.42 \\
\hline Moving light cans & 0.56 & 0.42 & 0.65 & 0.45 \\
\hline Moving I lb cans & 0.45 & 0.40 & 0.61 & 0.45 \\
\hline
\end{tabular}

Table 3. Intra-rater analysis: range of ICC parameters of each item in the reliability study JTHFT-I in rheumatoid arthritis population.

\begin{tabular}{|c|c|c|c|c|c|c|c|c|}
\hline & \multicolumn{4}{|c|}{ Non-dominant hand } & \multicolumn{4}{|c|}{ Dominant hand } \\
\hline & Test & Retest & ICC & $95 \% \mathrm{Cl}$ & Test & Retest & ICC & $95 \% \mathrm{Cl}$ \\
\hline Writing a 24-letter & $34.90 \pm 17.89$ & $40.32 \pm 12.24$ & 0.346 & $(-0.11$ to 0.624$)$ & $|4.1| \pm 6.47$ & $13.35 \pm 5.39$ & 0.625 & (0.036 to 0.891$)$ \\
\hline Stacking checkers & $5.01 \pm 2.11$ & $5.58 \pm 1.85$ & 0.913 & $(0.825$ to 0.958$)$ & $4.48 \pm 0.85$ & $4.71 \pm 1.50$ & 0.901 & (0.036 to 0.891$)$ \\
\hline $\begin{array}{l}\text { Turning over } \\
\text { a } 3 \times 5^{\prime \prime} \text { card }\end{array}$ & $6.95 \pm 1.94$ & $6.78 \pm 1.86$ & 0.927 & (0.853 to 0.965$)$ & $6.34 \pm 1.14$ & $5.55 \pm 1.30$ & 0.901 & (0.654 to 0.975$)$ \\
\hline $\begin{array}{l}\text { Pick up small } \\
\text { common object }\end{array}$ & $\mathrm{II} .17 \pm 7.0 \mathrm{I}$ & $9.08 \pm 2.35$ & 0.487 & $(0.159$ to 0.718$)$ & $7.42 \pm 1.80$ & $7.01 \pm 2.19$ & 0.862 & (0.654 to 0.975$)$ \\
\hline $\begin{array}{l}\text { Simulate feeding } \\
\text { using teaspoon }\end{array}$ & $5.28 \pm 1.46$ & $4.61 \pm 1.13$ & 0.829 & (0.672 to 0.915$)$ & $4.40 \pm 1.30$ & $4.43 \pm I .8 I$ & 0.826 & (0.559 to 0.964$)$ \\
\hline Moving light cans & $4.01 \pm 1.00$ & $4.04 \pm 1.07$ & 0.841 & $(0.691$ to 0.920$)$ & $3.92 \pm 1.04$ & $4.09 \pm 2.31$ & 0.921 & (0.717 to 0.980$)$ \\
\hline Moving I lb cans & $4.27 \pm 1.25$ & $4.30 \pm 1.29$ & 0.721 & (0.492 to 0.857$)$ & $3.86 \pm 0.94$ & $4.15 \pm 1.47$ & 0.972 & (0.892 to 0.993$)$ \\
\hline
\end{tabular}

ICC: intra-class correlation coefficient; $\mathrm{Cl}$ : confidence interval.

Table 4. Inter-rater analysis: range of ICC parameters of each item in the reliability study JTHFT-I in rheumatoid arthritis population.

\begin{tabular}{|c|c|c|c|c|c|c|c|c|}
\hline & \multicolumn{4}{|c|}{ Non-dominant hand } & \multicolumn{4}{|c|}{ Dominant hand } \\
\hline & Test & Retest & ICC & $95 \% \mathrm{Cl}$ & Test & Retest & ICC & $95 \%$ IC \\
\hline Writing a 24-letter & $40.49 \pm 13.03$ & $40.49 \pm 13.03$ & 0.778 & $(0.584-0.888)$ & $15.56 \pm 5.48$ & $|7.73 \pm 8.6|$ & 0.658 & $(0.092-0.902)$ \\
\hline Stacking checkers & $5.57 \pm 2.14$ & $5.57 \pm 2.14$ & 0.985 & $(0.970-0.993)$ & $4.99 \pm 0.78$ & $5.04 \pm 2.48$ & 0.964 & $(0.863-0.991)$ \\
\hline $\begin{array}{l}\text { Turning over } \\
\text { a } 3 \times 5^{\prime \prime} \text { card }\end{array}$ & $6.17 \pm 1.13$ & $6.17 \pm 1.13$ & 0.484 & $(0.155-0.716)$ & $6.17 \pm 0.64$ & $6.43 \pm 2.00$ & 0.446 & $(0.213-0.836)$ \\
\hline $\begin{array}{l}\text { Pick up small } \\
\text { common object }\end{array}$ & $11.93 \pm 11.18$ & $11.93 \pm 11.18$ & 0.412 & $(0.066-0.669)$ & $7.74 \pm 1.77$ & $7.90 \pm 3.55$ & 0.412 & $(0.252-0.813)$ \\
\hline $\begin{array}{l}\text { Simulate feeding } \\
\text { using teaspoon }\end{array}$ & $5.71 \pm 1.45$ & $5.7 \mathrm{I} \pm 1.45$ & 0.792 & $(0.607-0.895)$ & $4.51 \pm 0.84$ & $4.83 \pm 2.29$ & 0.797 & $(0.377-0.945)$ \\
\hline Moving light cans & $3.86 \pm 0.94$ & $3.86 \pm 0.94$ & 0.798 & $(0.618-0.899)$ & $3.93 \pm 0.76$ & $4.80 \pm 3.83$ & 0.807 & $(0.399-0.948)$ \\
\hline $\begin{array}{l}\text { Moving large } \\
\text { weighted cans }\end{array}$ & $4.12 \pm 1.22$ & $4.12 \pm 1.22$ & 0.818 & $(0.652-0.909)$ & $3.89 \pm 0.67$ & $4.40 \pm 2.28$ & 0.821 & $(0.432-0.953)$ \\
\hline
\end{tabular}

ICC: intra-class correlation coefficient; $\mathrm{Cl}$ : confidence interval.

the JTHFT-IT and the other instrument related to strength (the dynamometer), Pearson's coefficient showed statistically significant values ranging between -0.14 and -0.59 for the dominant hand and between -0.23 and -0.59 for the non-dominant hand (see Table 5).

\section{Discussion}

The aim of the study was to evaluate the psychometric properties of the JTHFT-IT in a population diagnosed with RA. The results of our study show that the JTHFT-IT is a reliable and valid instrument for the 
Table 5. Gold standard analysis: Pearson's correlation coefficient between the JTHFT-I and the dynamometer.

\begin{tabular}{lll}
\hline & $\begin{array}{l}\text { Non-dominant } \\
\text { hand }\end{array}$ & $\begin{array}{l}\text { Dominant } \\
\text { hand }\end{array}$ \\
\hline Writing a 24-letter & $-0.14^{\mathrm{a}}$ & $-0.23^{\mathrm{b}}$ \\
Stacking checkers & $-0.59^{\mathrm{b}}$ & -0.46 \\
Turning over a $3 \times 5^{\prime \prime}$ card & -0.43 & $-0.39^{\mathrm{b}}$ \\
Pick up small common object & $-0.43^{\mathrm{a}}$ & $-0.55^{\mathrm{b}}$ \\
Simulate feeding using teaspoon & $-0.42^{\mathrm{b}}$ & $-0.42^{\mathrm{b}}$ \\
Moving light cans & $-0.40^{\mathrm{b}}$ & $-0.42^{\mathrm{b}}$ \\
Moving large weighted cans & $-0.50^{\mathrm{b}}$ & $-0.59^{\mathrm{b}}$ \\
\hline
\end{tabular}

${ }^{a}$ Correlation is significant at the 0.05 level (two-tailed).

${ }^{b}$ Correlation is significant at the 00.01 level (two-tailed).

Italian population with RA. To evaluate the consistency of the scale, Cronbach's alpha coefficient was used, reporting a value of 0.53 for the dominant hand and 0.46 for the non-dominant hand. From the evaluation of the item-total correlation, it was observed that the first item of the test (writing a 24-letter sentence) had a different weight compared to the others. The results of this study are in line with previous studies; for example, in a Portuguese study, the writing item was slightly less consistent than the others. ${ }^{9}$ The authors attributed this result to the levels of education and language disorders associated with the post-stroke population analyzed in their study. It has been demonstrated that this item requires the longest time for the participant to finish the task, either with the dominant or non-dominant hand. Indeed, in the same Portuguese study from Ferreiro et al., it was reported that there were no significant differences between the scores obtained in the item "writing a sentence" for the participants with lower and higher levels of education or in the participants performing the task with the paretic, dominant hand compared to those performing the test with the paretic, non-dominant hand. This item obviously has a greater temporal importance than the others. If we decide to eliminate the first item, for both the dominant and non-dominant hands, the Cronbach's alpha values would reach 0.91 and 0.87 , respectively. To evaluate the test-retest reliability, ICC $(95 \%)$ was used with an average result of 0.85 (range: 0.81-0.91). Among the seven subtests, the writing subtest had relatively lower intra-rater $(0.34-0.62)$ reliability.

Another aspect to consider is that nowadays very few people write, especially if they have a hand condition that limits this. This could have affected the writing item. However, even though these days we have technological tools that assist with writing and this item no longer represents a modern key functional item, writing cannot be totally avoided and the writing task is still one of the most complete activities for the upper limb including a wide variety of movement. This is an important aspect to consider as many of these objective functional tests were developed long ago before we had access to technology.

To assess the validity of the scale, Pearson's correlation was also calculated and showed a strong negative association between the total score of the JTHFT-IT with the dynamometer, confirming as expected that increased time is associated with lower grip strength. "Picking up small common objects" for the dominant hand and "simulated page turning" for the nondominant hand showed no association. This is likely related to the fact that grip strength is not as relevant for the completion of these activities; however, from the evaluation with the dynamometer, it is possible to state that the JTHFT-IT shows concurrent validity with the Jamar dynamometer.

We agree with previous authors by acknowledging that the JTHFT has some limitations. ${ }^{11,12,14}$ The test rates speed, but does not rate different strategies of task performance. Different compensation mechanisms for positioning the upper limb during the JTHFT will not be reflected in the scores. Hence, it is important to provide appropriate instructions before starting the test and to ask patients to not change their strategy while being tested or, in clinical trials that use the JTHFT score as an endpoint, to not change strategies in followup evaluations. Furthermore, patients with moderate to severe functional impairment are often not testable with the JTHFT. Therefore, the test is appropriate for evaluating dexterity only in patients with slight to moderate hand disability. The main advantage of the JTHFT is to provide an objective measure of hand function by employing functionally relevant tasks that have good intra- and inter-rater reliability. Thanks to the results obtained by the current study, it is possible to state that the JTHFT-IT scale is a reliable test for assessing hand skills for daily life activities in people diagnosed with RA with a slight to moderate hand disability.

The present study has some limitations. Consistent with previous studies grip strength has been tested with the Jamar but bearing in mind that we were assessing fine hand use, inclusion of the pinch gauge could have been interesting. Furthermore, the time that participants had suffered from RA was not considered, and excluding those who had high level of pain could have compromised the generalization of results. In addition, it would have been interesting to analyze the JTHFTIT's concurrent validity by comparing it with another outcome measure for hand function, such as the Wolf Motor Function Test or the Disabilities of the Arm, Shoulder and Hand Outcome Measure. ${ }^{20}$ Moreover, further study could analyze the JTHFT-IT's construct validity, comparing it with performance outcome 
measures on responsiveness after rehabilitation treatment. Furthermore, it was not possible to compare timed performance between people with RA and healthy participants due to the absence of a control group. However, the normative data for the JTHFTIT is available in the literature ${ }^{10}$ for such comparisons and analyses.

\section{Conclusion}

In conclusion, it is possible to state that the JTHFT-IT is a useful scale for assessing the functioning of the hand in everyday activities in people with RA. However, based on our results, the authors recommend paying attention in choosing this tool for individuals with RA. The time used to complete the first task "write a letter" should be considered when using this tool in this population. The weight of this item compared to the others makes this tool not very recommendable for research. However, despite many authors claiming that timed performance tests alone should not be used to assess efficacy of treatments in hand surgery, the authors think that the JTHFT-IT is very suitable for clinic assessments because the objects used in the test can be easily purchased, and the implementation of the JTHFT-IT is inexpensive. Whilst no test used in isolation can provide a realistic assessment of hand function, it is important to consider the potential usefulness of JTHFT in a battery of tests. ${ }^{21}$ The instructions are simple and straightforward, and expertise in administering 9 the test is not time-consuming. Another important advantage of the JTHFT scale is the evaluation of movements related to activities of daily living, which makes it a perfect tool to use in a rehabilitation program for people with RA to assess the individual at baseline, register improvements, and as an outcome measure.

\section{Acknowledgments}

None.

\section{Declaration of Conflicting Interests}

The author(s) declared no potential conflicts of interest with respect to the research, authorship, and/or publication of this article.

\section{Funding}

The author(s) received no financial support for the research, authorship, and/or publication of this article.

\section{Ethical approval}

We certify that all applicable institutional and governmental regulations concerning the ethical use of human volunteers were followed during the course of this research.
All procedures followed were in accordance with the ethical standards of the responsible committee on human experimentation (institutional and national) and with the Helsinki Declaration of 1975, as revised in 2008.

\section{Guarantor}

GG.

\section{Contributorship}

GG, AS, LF, MS: conception and design of the study, analysis and interpretation of data; AB, MN, GC: analysis and interpretation of data, drafted the manuscript. MT, AnS: revised the manuscript. All authors read and approved the final manuscript.

\section{Informed consent}

Written informed consent was obtained from the patient(s) for their anonymized information to be published in this article.

\section{ORCID iD}

Marco Tofani (D) http://orcid.org/0000-0003-2071-4513

Giovanni Galeoto (D) http://orcid.org/0000-0002-9043-5686

\section{References}

1. World Health Organization. Chronic diseases and health promotion. Geneva: World Health Organization (accessed 27 December 2018).

2. Svensson E. Hand function in children and in persons with neurological disorders: aspects of movement control and evaluation of measurements. Sweden: Umeå University, 2009.

3. Poole JL. Measures of hand function: Arthritis Hand Function Test (AHFT), Australian Canadian Osteoarthritis Hand Index (AUSCAN), Cochin Hand Function Scale, Functional Index for Hand Osteoarthritis (FIHOA), Grip Ability Test (GAT), Jebsen Hand Function Test (JHFT), and Michigan Hand Outcomes Questionnaire (MHQ). Arthritis Care Res 2011; 63(2): S189-99.

4. Resnik L, Borgia M, Silver B, et al. Systematic review of measures of impairment and activity limitation for persons with upper limb trauma and amputation. Arch Phys Med Rehabil 2017; 98(9).

5. Jebsen RH, Taylor N, Trieschmann RB, et al. An objective and standardized test of hand function. Arch Phys Med Rehabil 1969;

6. Santisteban L, Térémetz M, Bleton JP, et al. Upper limb outcome measures used in stroke rehabilitation studies: a systematic literature review. PLoS One 2016; https://doi. org/10.1371/journal.pone.0154792.

7. Maas F. An interim Australian version of the Jebsen test of hand function. Aust J Physiother 1982; 28(2): 23-9.

8. Li-Tsang CWP, Chan SCC, Chan SYY, et al. The Hong Kong Chinese version of the Jebsen Hand Function Test: inter-rater and test-retest reliabilities. Hong Kong $J$ Occup Ther 2004; 14(1). 
9. Ferreiro KN, dos Santos RL and Conforto AB. Psychometric properties of the Portuguese version of the Jebsen-Taylor test for adults with mild hemiparesis. Braz J Phys Ther 2010;

10. Culicchia G, Nobilia M, Asturi M, et al. Cross-cultural adaptation and validation of the Jebsen-Taylor Hand Function Test in an Italian population. Rehabil Res Pract 2016;

11. Artilheiro MC, Fávero FM, Caromano FA, et al. Reliability, validity and description of timed performance of the Jebsen-Taylor Test in patients with muscular dystrophies. Braz J Phys Ther 2018;

12. Allgöwer K and Hermsdörfer J. Fine motor skills predict performance in the Jebsen-Taylor Hand Function Test after stroke. Clin Neurophysiol 2017;

13. Mak MKY, Lau ETL, Tam VWK, et al. Use of JebsenTaylor Hand Function Test in evaluating the hand dexterity in people with Parkinson's disease. J Hand Ther 2015;

14. Davis Sears E and Chung KC. Validity and responsiveness of the Jebsen-Taylor Hand Function Test. J Hand Surg Am 2010;

15. R.O.M.A. - Rehabilitation \& Outcome Measures Assessment, http://associazioneroma.org/ (accessed 27 December 2018).
16. Galeoto G, De Santis R, Marcolini A, et al. The informed consent in Occupational Therapy: proposal of forms. G Ital Med Lav Ergon 2016; 38: 107-115.

17. Galeoto G, Mollica R, Astorino O, et al. Il consenso informato in fisioterapia: Proposta di una modulistica. G Ital Med Lav Ergon 2015; 37: 245-254.

18. Hamilton GF, McDonald $\mathrm{C}$ and Chenier TC. Measurement of grip strength: validity and reliability of the sphygmomanometer and Jamar grip dynamometer. J Orthop Sport Phys Ther 2013,

19. Mokkink LB, Terwee CB, Patrick DL, et al. The COSMIN checklist for assessing the methodological quality of studies on measurement properties of health status measurement instruments: an international Delphi study. Qual Life Res 2010;

20. Berardi A, Dhrami L, Tofani M, et al. Cross-cultural adaptation and validation in the Italian population of the wolf motor function test in patients with stroke. Funct Neurol 2018; 33: 229-253.

21. van de Ven-Stevens LA, Munneke M, Terwee CB, et al. Clinimetric properties of instruments to assess activities in patients with hand injury: a systematic review of the literature. Arch Phys Med Rehabil 2009; 